\title{
Inactivation of apaziquone by haematuria: implications for the design of phase III clinical trials against non-muscle invasive bladder cancer
}

\author{
Roger M. Phillips ${ }^{1}$ (D) Paul M. Loadman ${ }^{2}$ (1) $\cdot$ Guru Reddy $^{3}$
}

Received: 11 October 2018 / Accepted: 8 March 2019 / Published online: 13 March 2019

(c) The Author(s) 2019

\begin{abstract}
Purpose Despite positive responses in phase II clinical trials, the bioreductive prodrug apaziquone failed to achieve statistically significant activity in non-muscle invasive bladder cancer in phase III trials. Apaziquone was administered shortly after transurethral resection and here we test the hypothesis that haematuria inactivates apaziquone.

Methods HPLC analysis was used to determine the ability of human whole blood to metabolise apaziquone ex vivo. An in vitro model of haematuria was developed and the response of RT112 and EJ138 cells following a 1-h exposure to apaziquone was determined in the presence of urine plus or minus whole blood or lysed whole blood.

Results HPLC analysis demonstrated that apaziquone is metabolised by human whole blood with a half-life of $78.6 \pm 23.0 \mathrm{~min}$. As a model for haematuria, incubation of cells in media containing up to $75 \%$ buffered $(\mathrm{pH} 7.4)$ urine and $25 \%$ whole blood was not toxic to cells for a 1-h exposure period. Whole blood $(5 \% \mathrm{v} / \mathrm{v})$ significantly $(p<0.01)$ reduced the potency of apaziquone in this experimental model. Lysed whole blood also significantly $(p<0.05)$ reduced cell growth, although higher concentrations were required to achieve an effect $(15 \% \mathrm{v} / \mathrm{v})$.

Conclusions The results of this study demonstrate that haematuria can reduce the potency of apaziquone in this experimental model. These findings impact upon the design of further phase III clinical trials and strongly suggest that apaziquone should not be administered immediately after transurethral resection of non-muscle invasive bladder cancer when haematuria is common.
\end{abstract}

Keywords Apaziquone $\cdot$ Non-muscle invasive bladder cancer $\cdot$ Haematuria

\section{Introduction}

Apaziquone, originally known as EO9 (3-hydroxy-5-aziridinyl-1- methyl-2-(1H-indole-4,7-dione)prop- $\beta$-en- $\alpha$-ol), has had a long and chequered history culminating in its clinical evaluation against non-muscle invasive bladder cancer [1,

Roger M. Phillips

r.m.phillips@hud.ac.uk

Paul M. Loadman

p.m.loadman@bradford.ac.uk

Guru Reddy

guru.reddy@sppirx.com

1 Department of Pharmacy, School of Applied Sciences, University of Huddersfield, Huddersfield HD1 3DH, UK

2 Institute of Cancer Therapeutics, University of Bradford, Bradford BD7 1DP, UK

3 Spectrum Pharmaceuticals Inc, Irvine, CA, USA
2]. Whilst its pharmacokinetic properties are undesirable for systemic administration, they are paradoxically advantageous in the treatment of non-muscle invasive bladder cancer (NMIBC) where intravesical administration ensures adequate delivery to the tumour site and any drug leaching out into the blood stream is rapidly removed leading to low risk of systemic side effects. Apaziquone is a bioreductive prodrug that requires enzymatic activation to DNA damaging species [2] and following the demonstration that NMIBC possesses the appropriate enzymology to activate apaziquone [3, 4], significant ablative activity against NMIBC marker lesions was reported in phase I and II clinical trials $[5,6]$. The level of activity observed in marker lesion studies was higher than that reported for other chemotherapy drugs and immune response modifiers [7] and 2-year response rates demonstrated that long-term responses were good in comparison to other ablative studies $[8,9]$. The results of two phase III clinical trials were, however, disappointing, and when analysed individually, both studies failed to reach 
statistical significance for the primary end point which was the 2 year recurrence rate [10].

To try and explain the stark differences in outcomes between the phase III trial and marker lesion studies, we focus in this study on key differences in the design of these clinical trials. The major difference between the two sets of studies was that a single dose of apaziquone was administered intravesically within $24 \mathrm{~h}$ of transurethral resection of bladder tumours (TURBT) in phase III studies, whereas apaziquone was administered weekly for 6 weeks starting 2 weeks after TURBT in the marker lesion studies. There is therefore a difference in the timing of drug administration relative to TURBT and a reduction in the cumulative dose given to patients in the phase III study. Haematuria is common following surgical resection of tumours and, in 2002, we demonstrated that apaziquone is rapidly metabolised by murine whole blood [11]. Whilst the context of these studies focused on the design of second-generation analogues of apaziquone that had better pharmacokinetic properties, this observation has direct relevance to the clinical problem outlined above. Administration of apaziquone immediately after surgery when haematuria is common could affect the potency and therefore efficacy of apaziquone. Post hoc analysis of the data generated in the phase III trial did in fact reveal that a subset of patients who received apaziquone within $30 \mathrm{~min}$ of TURBT had no difference in response rate compared to the placebo arm [10]. In contrast, patients who received apaziquone between 30 and 90 min after TURBT demonstrated a highly significant response to apaziquone in terms of 2-year recurrence rates. Our hypothesis therefore is that haematuria immediately after surgery causes a reduction in the efficacy of apaziquone when administered immediately after TURBT. In this study, experimental evidence is provided demonstrating that apaziquone is metabolised by human blood and this reduces the potency of apaziquone in an in vitro model of haematuria. These findings have implications for the design of future phase III clinical trials and these are discussed within.

\section{Materials and methods}

\section{Metabolism of apaziquone by human blood}

The metabolism of apaziquone by human whole blood was performed as described elsewhere [11]. Following informed consent, blood samples were obtained from healthy volunteers, collected in EDTA tubes [BD vacutainer K2E (EDTA)] and either used as 'whole blood' or plasma (obtained by centrifuging blood at $3000 \mathrm{~g}$ for $5 \mathrm{~min}$ ). Whole blood or plasma samples were spiked with apaziquone $(20 \mu \mathrm{M})$ and incubated at $37{ }^{\circ} \mathrm{C}$ for various times. Apaziquone was extracted from samples by the addition of ice-cold acetonitrile with a solvent/sample ratio of $2: 1$ and centrifuged at $7000 \mathrm{~g}$ for $5 \mathrm{~min}$ to remove precipitated proteins. Samples were analysed by reverse phase HPLC [12] using a LiChrosorb RP-18 column and a Waters 996 Photodiode Array detector. The mobile phase was phosphate buffer $(10 \mathrm{mM}, \mathrm{pH} 7.0) /$ methanol (57/43) and the flow rate was $1.2 \mathrm{ml} / \mathrm{min}$. Identical studies were conducted using phosphate-buffered saline (PBS at $\mathrm{pH}$ 7.4). PBS spiked with $20 \mu \mathrm{M}$ apaziquone $(t=0)$ was used as the $100 \%$ control and recovery from biological samples was expressed as a percentage of the PBS control.

\section{Cell lines and chemosensitivity studies}

RT112 and EJ138 human bladder carcinoma cell lines were obtained from ECACC and routinely maintained as monolayer cultures in RPMI1640/DMEM (50:50 mix) containing foetal calf serum $(10 \% \mathrm{v} / \mathrm{v})$ and L-glutamine $(2 \mathrm{mM})$. Purified, unformulated apaziquone was obtained from Spectrum Pharmaceuticals Inc. and stock solutions at $100 \mathrm{mM}$ were prepared in DMSO, aliquoted and stored at $-20{ }^{\circ} \mathrm{C}$. For chemosensitivity studies performed under standard cell culture conditions, cells were plated into 96-well plates at $2 \times 10^{3}$ cells per well and incubated overnight to adhere. The following day, cell culture media were removed and replaced with media containing a range of apaziquone concentrations (10-0.196 $\mu \mathrm{M}$ using a twofold serial dilution strategy). Cells were exposed to apaziquone for $1 \mathrm{~h}$ (to mimic the 1-h instillation protocol used in the clinic), following which they were washed three times with PBS before the addition of $200 \mu \mathrm{l}$ of media to each well. Cells were subsequently incubated at $37^{\circ} \mathrm{C}$ for $96 \mathrm{~h}$ before growth inhibition determination using the MTT assay as described elsewhere [12]. Briefly, culture media were removed from each well and replaced with $200 \mu \mathrm{l}$ of fresh media prior to the addition of $20 \mu \mathrm{l}$ of MTT $(5 \mathrm{mg} / \mathrm{ml})$. Following a 4-h incubation at $37^{\circ} \mathrm{C}$, media were removed and formazan crystals dissolved in $150 \mu \mathrm{l}$ of DMSO per well. The absorbance of the resulting solution was determined spectrophotometrically at $540 \mathrm{~nm}$ and cell growth was determined as the true absorbance of treated cells divided by the true absorbance of control cells and expressed as a percentage. Three independent experiments were performed and the results are presented as the mean $\mathrm{IC}_{50}$ values \pm standard deviation.

Apaziquone is known to be active against both aerobic and hypoxic cells [13], but all studies were conducted against aerobic cells for the following reasons. First, the phase III studies were conducted in patients that had all tumours surgically removed and therefore there were no solid masses where hypoxia could exist. Second, the vehicle used in the instillation was well oxygenated (in equilibrium with atmospheric conditions) and the administration of $40 \mathrm{ml}$ directly into the bladder would be expected to create local conditions that would be aerobic. Based on the above considerations, 
it would be unlikely that conditions in the bladder would be conducive to the hypoxia activation of apaziquone and this was therefore not evaluated.

\section{Chemosensitivity studies in the presence of urine and whole blood}

To determine the amount of blood and urine that cells in culture will tolerate, cells were exposed to varying amounts of urine or blood for $1 \mathrm{~h}$ and cell survival was determined $96 \mathrm{~h}$ later using the MTT assay as described above. Following informed consent, blood samples were obtained from healthy volunteers and placed into EDTA tubes. For studies using whole blood, samples were initially diluted 1:1 in cell culture media followed for subsequent twofold serial dilution in media to generate a range of blood dilutions (50-0.098\% $\mathrm{v} / \mathrm{v})$. Cell culture plates were set up as described above and following a 1-h exposure to media containing whole blood at different concentrations, cells were washed, culture media added $(200 \mu \mathrm{l} /$ well $)$ and incubated for a further $96 \mathrm{~h}$ before percentage growth inhibition was determined using the MTT assay as described above. In addition, as haemolysis is commonly observed in haematuria, similar studies were conducted using lysed whole blood (obtained by repeated cycles of rapid freezing in liquid nitrogen and thawing at $37^{\circ} \mathrm{C}$ ).

Mid-flow urine samples were obtained from healthy volunteers and used immediately. Urine samples were either applied directly to cells or $\mathrm{pH}$ adjusted to 7.4 using $\mathrm{NaOH}$ prior to addition to cells. Unbuffered or $\mathrm{pH}$-adjusted urine was diluted in culture media to give a range of urine concentrations and these were applied to cell cultures as described above. Following a 1-h incubation, cells were washed and culture media added $(200 \mu \mathrm{l} /$ well). Following a further $96-\mathrm{h}$ incubation at $37^{\circ} \mathrm{C}$, percentage cell growth was determined using the MTT assay as described above.

\section{Results}

\section{Metabolism of apaziquone by whole blood and plasma}

The metabolism of apaziquone in human whole blood, human plasma and PBS is presented in Fig. 1a. Whilst apaziquone is stable in PBS and plasma over a 2-h period, levels of apaziquone decrease significantly in a time-dependent manner (Fig. 1a). No metabolites (specifically the inactive products EO5A and EO9-Cl [14]) were observed on chromatograms (data not shown) suggesting that any active metabolites of apaziquone are irreversibly bound to cellular components of whole blood and remain within the protein precipitate.

\section{Response of EJ138 and RT112 cells to apaziquone}

The response of cell lines following a 1-h exposure to apaziquone are presented in Fig. 1b. Both cell lines are sensitive to apaziquone with $\mathrm{IC}_{50}$ values of $1.11 \pm 0.09$ and $0.915 \pm 0.291 \mu \mathrm{M}$ for RT112 and EJ138 cells, respectively. In both cell lines, a 1-h exposure to apaziquone at $5 \mu \mathrm{M}$ induces a 95\% growth inhibition, so this concentration was chosen for subsequent experiments to determine the effect of blood and urine on the activity of apaziquone.

\section{Response of EJ138 and RT112 cells to urine and whole blood}

The effect of whole blood and urine on the proliferation of cells is presented in Fig. 1c, d, respectively. The addition of whole blood onto cells for a period of $1 \mathrm{~h}$ has no effect on cell survival up to $25 \% \mathrm{v} / \mathrm{v}$. At $50 \% \mathrm{v} / \mathrm{v}$, however, substantial cell killing occurred along with problems with clotting in the wells. For subsequent experiments, therefore, the highest concentration of whole blood used was $25 \% \mathrm{v} / \mathrm{v}$. Whilst difficult to establish the clinical relevance of this concentration of whole blood in these experiments, it is known that haematuria following TURBT is both common and can vary between mild to gross haematuria that requires further medical intervention [15]. Exposure of cells to unbuffered urine (in the experiment in Fig. 1d, the $\mathrm{pH}$ of the urine was 5.93) led to a dose-dependent reduction in cell growth. Cells were however able to tolerate up to $90 \%$ urine once $\mathrm{pH}$ had been adjusted to $\mathrm{pH}$ 7.4. For subsequent experiments, $\mathrm{pH}$-adjusted urine $(\mathrm{pH} 7.4)$ at $75 \%(\mathrm{v} / \mathrm{v})$ was used.

In summary, the results presented in Fig. 1b-d define the parameters within which subsequent experiments were performed. These include (i) the concentration of apaziquone (5 $\mu \mathrm{M}$ ) that induces $>95 \%$ cell growth inhibition, (ii) an upper limit for the amount of whole blood that can be used (25\% $\mathrm{v} / \mathrm{v}$ ) without affecting cell growth and (iii) the amount of buffered urine that can be used without causing significant inhibition of cell growth $(75 \% \mathrm{v} / \mathrm{v})$.

\section{Response of EJ138 and RT112 cells to apaziquone in buffered urine and whole blood}

The results presented in Fig. 2a, b clearly demonstrate that the inclusion of whole blood (5\%) and buffered urine (75\%) significantly $(p<0.01)$ reduces the potency of apaziquone. Whilst apaziquone induces a $>95 \%$ cell killing in both RT112 and EJ138 cells in the absence of whole blood, the inclusion of whole blood $(5 \% \mathrm{v} / \mathrm{v})$ significantly increases cell survival in RT112 $(p=0.0029)$ and EJ138 $(p=0.0004)$ cells. The effect of buffered urine on the activity of apaziquone is negligible, as cell growth inhibition in the positive controls is similar to cell growth inhibition in media (compare 
Fig. 1 Metabolism of apaziquone by human blood and establishment of the haematuria model. a Time-dependent metabolism of apaziquone following incubation at $37^{\circ} \mathrm{C}$ in whole blood (filled circle), plasma (unfilled circle) and PBS (unfilled square). Each value represents the mean \pm standard deviation for three independent experiments. The response of EJ138 and RT112 cells following a 1-h exposure to EO9 is presented in $\mathbf{b}$. Values represent the mean \pm standard deviation for three independent experiments. The response of cells to whole blood and urine are presented in $\mathbf{c}$ and $\mathbf{d}$, respectively. Exposure times were $1 \mathrm{~h}$ and each result represents the mean \pm standard deviation for eight replicates
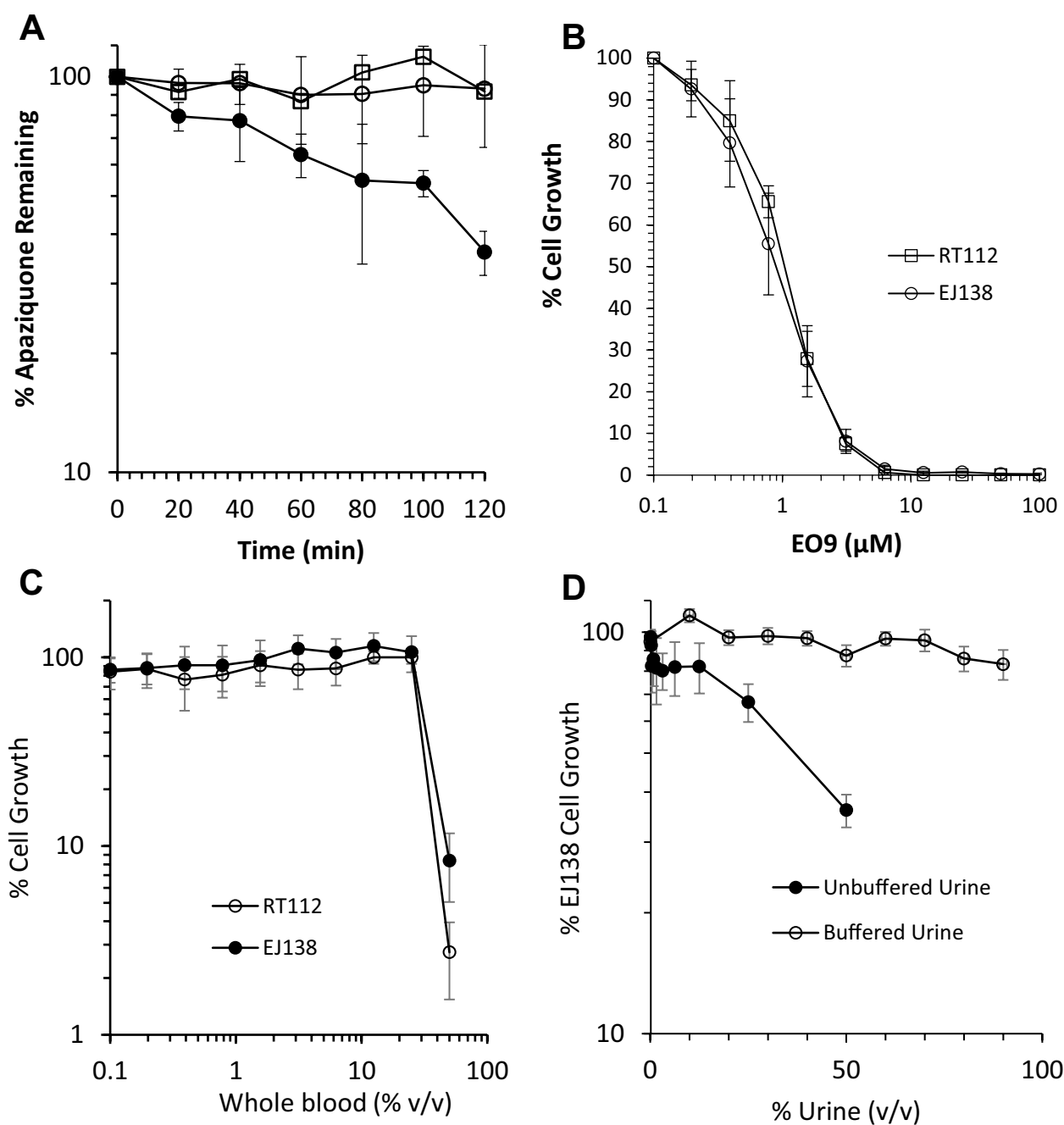

Fig. 2a, b with Fig. 1b). The results obtained using lysed whole blood are presented in Fig. 2c, d. In both cell lines, a small but statistically significant $(p<0.05)$ reduction in the potency of apaziquone was observed when lysed whole blood (at concentrations of $15 \%$ and above) was added to buffered urine. This effect was dose dependent with respect to the amount of lysed whole blood included in the assay. In contrast to the whole blood experiments where highly significant reductions in activity were observed at $5 \%$ whole blood, the effect of lysed whole blood on the activity of apaziquone was lower.

\section{Discussion}

The main reason for the change in the protocols between apaziquone phase III and marker lesion studies was to comply with current guidance for intravesical chemotherapy issued by the European Association of Urology (EAU) and American Urological Association (AUA). A series of studies indicate that a single instillation of chemotherapy immediately after resection reduces the risk of recurrence [16-19] with the most benefit seen with mitomycin $\mathrm{C}$ and epirubicin. The EAU guidelines therefore recommend immediate intravesical instillation of chemotherapy after surgical resection of low to intermediate risk NMIBC. The AUA guidelines differ slightly in that intravesical administration of chemotherapy (mitomycin $\mathrm{C}$ or epirubicin) should be considered within $24 \mathrm{~h}$ of surgical resection for low to intermediate risk NMIBC patients. Whilst there is strong clinical evidence for the immediate intravesical administration of mitomycin $\mathrm{C}$ or epirubicin after TURBT, the results of this study suggest that the same principles and guidance may not be applicable to apaziquone.

In contrast to the structurally related mitomycin $\mathrm{C}$ which is not metabolised by murine whole blood, our previous studies have demonstrated that apaziquone is rapidly metabolised by murine whole blood [11]. In this study we demonstrate that apaziquone is also metabolised by human blood (Fig. 1a), albeit at a reduced rate compared to murine blood. 
Fig. 2 Response of RT112 and EJ138 cells to EO9 in the presence and absence of whole blood and lysed whole blood. a, b Response of RT112 and EJ138, respectively, to a 1-h exposure to apaziquone $(5 \mu \mathrm{M})$ in buffered urine $(75 \%$ $\mathrm{v} / \mathrm{v})$ without (0) or with whole blood $(5 \% \mathrm{v} / \mathrm{v})$. Following drug exposure, cell growth was determined $96 \mathrm{~h}$ later using the MTT assay. c, d RT112 and EJ138 treated with apaziquone $(5 \mu \mathrm{M})$, urine $(75 \%)$ and various concentrations of lysed whole blood. Exposure to experimental conditions was for $1 \mathrm{~h}$, followed by a $96 \mathrm{~h}$ recovery period prior to the assessment of cell growth using the MTT assay. Control experiments (c) used media plus apaziquone only (no urine or lysed whole blood). Statistical analysis was performed using a paired $t$ test comparing the effects of each treatment with that of controls (** and $*$ denote statistical significance at $p<0.01$ and $p<0.05$, respectively)
A

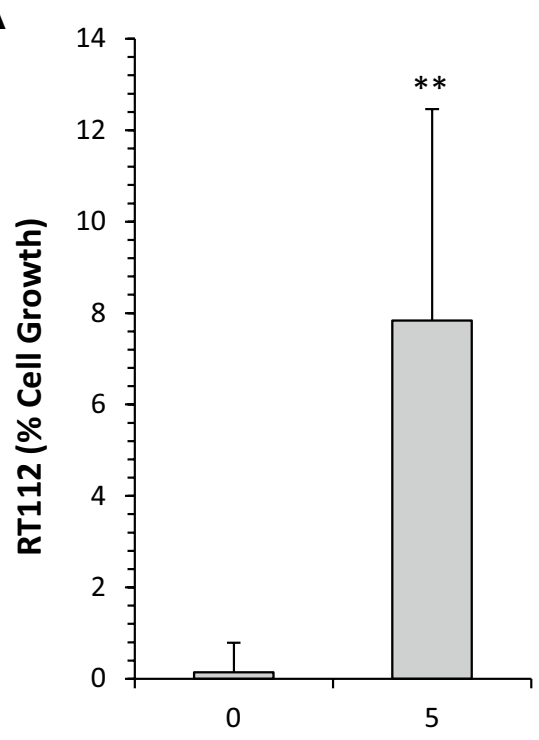

\% Whole Blood

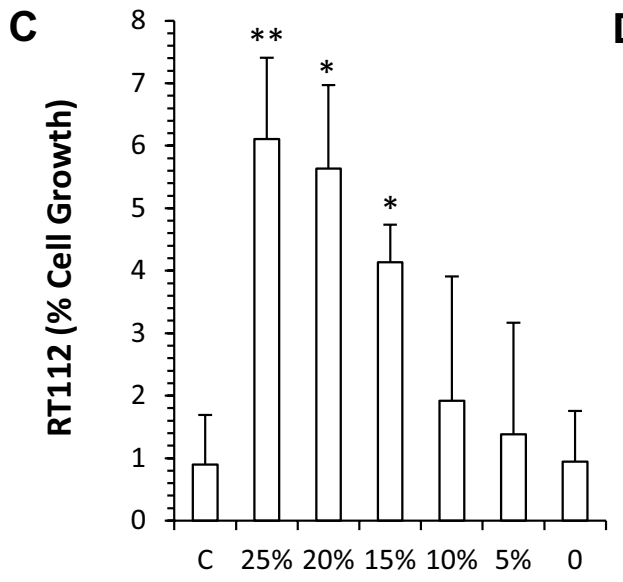

\% Lysed Whole Blood (v/v)

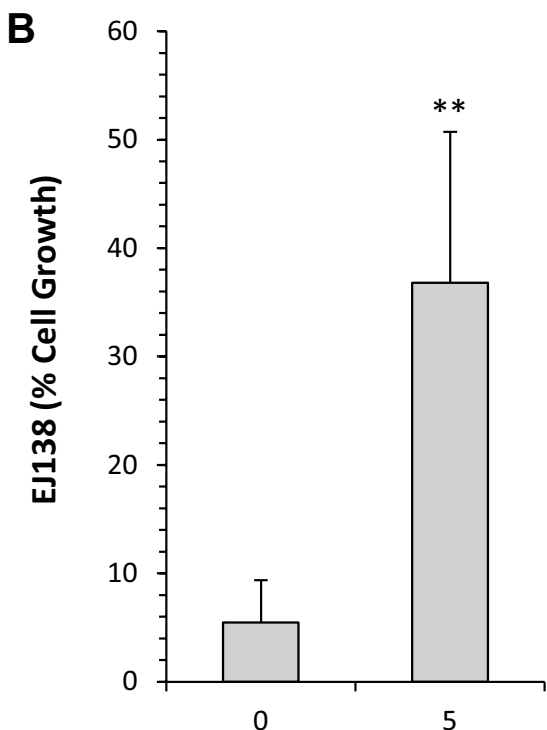

\% Whole Blood

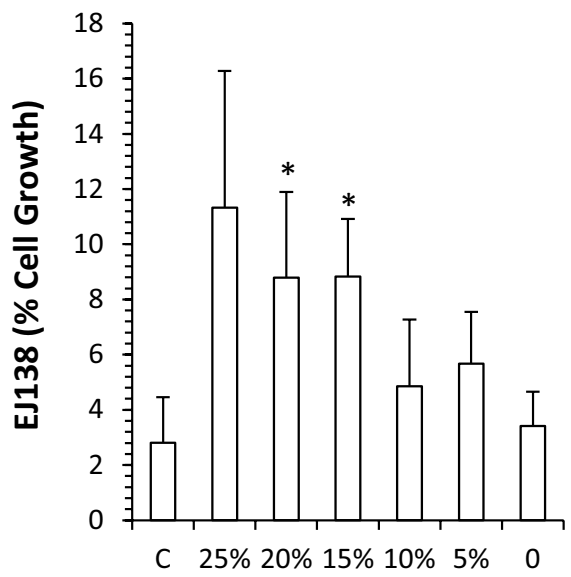

\% Lysed Whole Blood (v/v)
The fact that apaziquone is stable in both PBS and plasma suggests that chemical instability and protein binding are not responsible for the loss of apaziquone. Furthermore, the fact that no metabolites were detected using HPLC supports the argument that apaziquone is being metabolised to products that are irreversibly bound to cellular macromolecules that cannot be recovered using acetonitrile extraction techniques.

Apaziquone is a prodrug that requires enzymatic activation to generate cytotoxic intermediates with one and two electron oxidoreductases playing a prominent role in drug activation [2]. The identification of enzymes capable of metabolising apaziquone in human blood has not been elucidated in this study, but it is important to recognise that the RBC component of whole blood is not just concerned with the transport and release of oxygen but it has other metabolic functions that impact upon the pharmacokinetic and pharmacodynamic property of drugs including anticancer agents [20,21]. These metabolic functions extend to redox reactions, nitric oxide metabolism and glutathione metabolism [22, 23], all of which can affect the pharmacology of anti-cancer drugs. Furthermore, red blood cells are known to contain high levels of NADH cytochrome b5 reductase (CYB5R), an enzyme that has been implicated in the bioreductive activation of quinone-based drugs including mitomycin C $[24,25]$. A direct role for CYB5R in the activation of apaziquone has not however been established and further studies are required to fully understand the detailed metabolism of apaziquone by human whole blood. The impact of this study however resides in the development of an in vitro model of haematuria and the demonstration that the efficacy of apaziquone is reduced under experimental conditions that mimic haematuria. This study suggests that 
the administration of apaziquone immediately after TURBT when haematuria is common could reduce the efficacy of apaziquone. Whilst the level of haematuria was not reported in phase III clinical trials, the presence of whole blood or lysed whole blood in the bladder immediately (less than $30 \mathrm{~min}$ ) after TURBT is a common observation and therefore a potential contributing factor that could explain the reduced efficacy of apaziquone observed in phase III clinical trials.

With regard to the continued development of apaziquone, a further phase III clinical trial is required to address the post hoc analysis of the results and subsequent hypotheses generated during the previous phase III studies (FDA briefing document). Based on the results of this study, immediate instillation of apaziquone should not be performed with a preference for instillation $60 \pm 30 \mathrm{~min}$ after surgery when haematuria is reduced or non-existent. Another potential way of circumventing the effects of haematuria is to increase the dose administered. A dose escalation was performed in a clinical pilot study [5] and $4 \mathrm{mg} / 40 \mathrm{ml}$ was selected as the dose that induced no systemic or local side effects. This dose was used for all subsequent clinical studies including the phase III clinical trials. A dose of $8 \mathrm{mg} / 40 \mathrm{ml}$ induced some local toxicities (grade $2 / 3$ dysuria and haematuria), but was also well tolerated.

In conclusion, the results of this study have demonstrated that haematuria can reduce the efficacy of apaziquone in experimental models in vitro and this is a potential explanation for the poor efficacy of apaziquone when administered within $30 \mathrm{~min}$ of TURBT. These results were used to inform the design of the current active phase III clinical trial (NCT03224182) where apaziquone is administered intravesically $60 \pm 30 \mathrm{~min}$ after TURBT at a dose of $8 \mathrm{mg} / 40 \mathrm{ml}$.

Acknowledgements The author (RMP) would like to acknowledge financial support from Spectrum Pharmaceuticals Inc. for the conduct of the experiments described in this manuscript.

\section{Compliance with ethical standards}

Conflict of interest Guru Reddy is an employee and shareholder of Spectrum Pharmaceuticals Inc.

Ethical approval All procedures performed in studies involving human participants were in accordance with the ethical standards of the institutional and/or national research committee and with the 1964 Helsinki Declaration and its later amendments or comparable ethical standards.

Open Access This article is distributed under the terms of the Creative Commons Attribution 4.0 International License (http://creativeco mmons.org/licenses/by/4.0/), which permits unrestricted use, distribution, and reproduction in any medium, provided you give appropriate credit to the original author(s) and the source, provide a link to the Creative Commons license, and indicate if changes were made.

\section{References}

1. Phillips RM, Hendriks HR, Peters GJ, Pharmacology E, Molecular Mechanism G (2013) EO9 (Apaziquone): from the clinic to the laboratory and back again. Br J Pharmacol 168(1):11-18. https:// doi.org/10.1111/j.1476-5381.2012.01996.x

2. Phillips RM, Hendriks HR, Sweeney JB, Reddy G, Peters GJ (2017) Efficacy, pharmacokinetic and pharmacodynamic evaluation of apaziquone in the treatment of non-muscle invasive bladder cancer. Expert Opin Drug Metab Toxicol 13(7):783-791. https://doi.org/10.1080/17425255.2017.1341490

3. Basu S, Brown JE, Flannigan GM, Gill JH, Loadman PM, Martin SW, Naylor B, Scally AJ, Seargent JM, Shah T, Puri R, Phillips RM (2004) Immunohistochemical analysis of NAD(P) $\mathrm{H}$ :quinone oxidoreductase and NADPH cytochrome P450 reductase in human superficial bladder tumours: relationship between tumour enzymology and clinical outcome following intravesical mitomycin C therapy. Int J Cancer 109(5):703-709. https://doi.org/10.1002/ijc.20005

4. Choudry GA, Stewart PA, Double JA, Krul MR, Naylor B, Flannigan GM, Shah TK, Brown JE, Phillips RM (2001) A novel strategy for NQO1 (NAD(P)H:quinone oxidoreductase, EC 1.6.99.2) mediated therapy of bladder cancer based on the pharmacological properties of EO9. Br J Cancer 85(8):1137-1146. https://doi.org/10.1054/bjoc.2001.2056

5. Puri R, Palit V, Loadman PM, Flannigan M, Shah T, Choudry GA, Basu S, Double JA, Lenaz G, Chawla S, Beer M, Van Kalken C, de Boer R, Beijnen JH, Twelves CJ, Phillips RM (2006) Phase I/II pilot study of intravesical apaziquone (EO9) for superficial bladder cancer. J Urol 176(4 Pt 1):1344-1348. https://doi.org/10.1016/j.juro.2006.06.047

6. van der Heijden AG, Moonen PM, Cornel EB, Vergunst H, de Reijke TM, van Boven E, Barten EJ, Puri R, van Kalken CK, Witjes JA (2006) Phase II marker lesion study with intravesical instillation of apaziquone for superficial bladder cancer: toxicity and marker response. J Urol 176(4 Pt 1):1349-1353. https://doi. org/10.1016/j.juro.2006.06.007 (discussion 1353)

7. Gofrit ON, Zorn KC, Shikanov S, Steinberg GD (2010) Marker lesion experiments in bladder cancer-what have we learned? J Urol 183(5):1678-1684. https://doi.org/10.1016/j. juro.2009.12.104

8. Hendricksen K, van der Heijden AG, Cornel EB, Vergunst H, de Reijke TM, van Boven E, Smits GA, Puri R, Gruijs S, Witjes JA (2009) Two-year follow-up of the phase II marker lesion study of intravesical apaziquone for patients with non-muscle invasive bladder cancer. World J Urol 27(3):337-342. https:// doi.org/10.1007/s00345-009-0382-4

9. Jain A, Phillips RM, Scally AJ, Lenaz G, Beer M, Puri R (2009) Response of multiple recurrent TaT1 bladder cancer to intravesical apaziquone (EO9): comparative analysis of tumor recurrence rates. Urology 73(5):1083-1086. https://doi.org/10.1016/j.urolo gy.2007.12.062

10. Karsh L, Shore N, Soloway M, Bhat G, Reddy G, Leu SY, Witjes JA (2018) Double-blind, randomized, placebo-controlled studies evaluating Apaziquone (E09, Qapzola) intravesical instillation post transurethral resection of bladder tumors for the treatment of low-risk non-muscle invasive bladder cancer. Bladder Cancer 4(3):293-301. https://doi.org/10.3233/BLC180166

11. Loadman PM, Bibby MC, Phillips RM (2002) Pharmacological approach towards the development of indolequinone bioreductive drugs based on the clinically inactive agent EO9. Br J Pharmacol 137(5):701-709. https://doi.org/10.1038/sj.bjp.0704916 
12. Phillips RM, Hulbert PB, Bibby MC, Sleigh NR, Double JA (1992) In vitro activity of the novel indoloquinone EO-9 and the influence of $\mathrm{pH}$ on cytotoxicity. Br J Cancer 65(3):359-364

13. Phillips RM (2016) Targeting the hypoxic fraction of tumours using hypoxia-activated prodrugs. Cancer Chemother Pharmacol 77(3):441-457. https://doi.org/10.1007/s00280-015-2920-7

14. Vainchtein LD, Rosing H, Mirejovsky D, Lenaz L, Schellens JH, Beijnen JH (2007) Stability experiments in human urine with EO9 (apaziquone): a novel anticancer agent for the intravesical treatment of bladder cancer. J Pharm Biomed Anal 43(1):285-292. https://doi.org/10.1016/j.jpba.2006.06.044

15. Ghali F, Moses RA, Raffin E, Hyams ES (2016) What factors are associated with unplanned return following transurethral resection of bladder tumor? An analysis of a large single institution's experience. Scand J Urol 50(5):370-373. https://doi.org/10.1080/21681 805.2016.1201856

16. Abern MR, Owusu RA, Anderson MR, Rampersaud EN, Inman BA (2013) Perioperative intravesical chemotherapy in non-muscle-invasive bladder cancer: a systematic review and meta-analysis. J Natl Compr Canc Netw 11(4):477-484

17. Perlis N, Zlotta AR, Beyene J, Finelli A, Fleshner NE, Kulkarni GS (2013) Immediate post-transurethral resection of bladder tumor intravesical chemotherapy prevents non-muscle-invasive bladder cancer recurrences: an updated meta-analysis on 2548 patients and quality-of-evidence review. Eur Urol 64(3):421-430. https://doi.org/10.1016/j.eururo.2013.06.009

18. Sylvester RJ, Oosterlinck W, Holmang S, Sydes MR, Birtle A, Gudjonsson S, De Nunzio C, Okamura K, Kaasinen E, Solsona E, Ali-El-Dein B, Tatar CA, Inman BA, N'Dow J, Oddens JR, Babjuk M (2016) Systematic review and individual patient data meta-analysis of randomized trials comparing a single immediate instillation of chemotherapy after transurethral resection with transurethral resection alone in patients with stage pTa-pT1 urothelial carcinoma of the bladder: which patients benefit from the instillation? Eur Urol 69(2):231-244. https://doi.org/10.1016/j. eururo.2015.05.050

19. Sylvester RJ, Oosterlinck W, van der Meijden AP (2004) A single immediate postoperative instillation of chemotherapy decreases the risk of recurrence in patients with stage Ta T1 bladder cancer: a meta-analysis of published results of randomized clinical trials. J Urol 171(6 Pt 1):2186-2190 (quiz 2435)

20. Cossum PA (1988) Role of the red blood cell in drug metabolism. Biopharm Drug Dispos 9(4):321-336

21. Hinderling PH (1997) Red blood cells: a neglected compartment in pharmacokinetics and pharmacodynamics. Pharmacol Rev 49(3):279-295

22. Kennett EC, Kuchel PW (2003) Redox reactions and electron transfer across the red cell membrane. IUBMB Life 55(7):375385. https://doi.org/10.1080/15216540310001592843

23. Kuhn V, Diederich L, Keller TCS, Kramer CM, Luckstadt W, Panknin C, Suvorava T, Isakson BE, Kelm M, Cortese-Krott MM (2017) Red blood cell function and dysfunction: redox regulation, nitric oxide metabolism, anemia. Antioxid Redox Signal 26(13):718-742. https://doi.org/10.1089/ars.2016.6954

24. Borgese N, Pietrini G, Gaetani S (1987) Concentration of NADHcytochrome b5 reductase in erythrocytes of normal and methemoglobinemic individuals measured with a quantitative radioimmunoblotting assay. J Clin Invest 80(5):1296-1302. https://doi. org/10.1172/JCI113205

25. Hodnick WF, Sartorelli AC (1993) Reductive activation of mitomycin $\mathrm{C}$ by NADH:cytochrome b5 reductase. Cancer Res 53(20):4907-4912

Publisher's Note Springer Nature remains neutral with regard to jurisdictional claims in published maps and institutional affiliations. 